\title{
General practice and teaching hospital use of barium meal examinations in the City and Hackney Health District
}

\author{
B.G. Conry ${ }^{1}$, A.M. McLean ${ }^{1}$ and M.J.G. Farthing ${ }^{2}$ \\ Departments of ${ }^{1}$ Radiology and ${ }^{2}$ Gastroenterology, St Bartholomew's Hospital, West Smithfield, London \\ ECIA $7 B E, U K$.
}

\begin{abstract}
Summary: The value of barium meal examination in the management of younger patients with dyspepsia has been seriously questioned as diagnostic yield is reported to be low with only minor abnormalities detected. Our 9 month survey of general practice and hospital out-patient use of barium meal examination in the City and Hackney Health District during 1983-84 shows that $51 \%$ of patients investigated were less than 50 years and $20 \%$ less than 30 years of age, suggesting that clinicians have not heeded these warnings. However, $\mathbf{3 0} \%$ of the younger patients had barium meal mucosal abnormalities. Over all age groups abnormalities were more prevalent in men and in general practice rather than hospital out-patient referrals (59\% vs $45 \% ; P<0.02)$. Previous studies may therefore have underestimated the prevalence of barium meal abnormalities in younger patients, and continued use of this examination in such patients may indicate that clinicians have found the results helpful in patient management.
\end{abstract}

\section{Introduction}

For almost twenty years most general practitioners (GP) in the United Kingdom have had open access to barium meal examinations in hospital radiology departments. Several reports have demonstrated that their requests are both as appropriate and productive as those of their hospital colleagues (Cook, 1976; Wright et al., 1977; Haines et al., 1980). Immediately before the widespread introduction of $\mathrm{H}_{2}$-receptor antagonist drugs, the usefulness of the barium meal examination in dyspeptics less than 50 years of age was questioned (Mead et al., 1977). Overall, examinations in these individuals produced few abnormalities or management decision changes.

Since the advent of $\mathrm{H}_{2}$-receptor antagonists, no assessment has been made of the usage and diagnostic yield of barium meal examinations in clinical practice. We have therefore surveyed barium meal usage by general practitioners and hospital doctors, with particular emphasis on the prevalence of radiological abnormalities and their relationship to age.

\section{Patients and methods}

The results of barium meal examinations requested by GPs during a 9 month period from June 1983 to

Correspondence: M.J.G. Farthing, M.D., M.R.C.P. Accepted: 12 November 1985
February 1984 were reviewed. One hundred and sixty four examinations were performed which represented $16.7 \%$ of the total barium meal workload of the Department of Radiology at St. Bartholomew's Hospital. Twelve of these examinations were requested by GPs outside our health district and were not included in the study. One hundred and fifty two age and sexmatched hospital outpatients (OP) with epigastric pain were randomly selected from the 597 individuals who had had out-patient barium meal examinations performed in the same period. All patients were examined by a double-contrast technique and the waiting period was the same for both GP and hospital OP groups, namely 3 weeks. GPs did not have open access to an upper gastrointestinal endoscopy service.

Barium meal examinations were classified according to whether the findings were normal, abnormal (subdivided into mucosal and structural/functional categories, see Table I) or equivocal. Equivocal reports were those in which abnormality could not be definitely excluded for technical or other reasons.

\section{Results}

Barium meal examinations requested by GPs produced a significantly higher proportion of abnormal examinations (59\%) compared to age and sexmatched hospital OP referrals $\left(45 \% ; \chi^{2}=6.3\right.$, $P<0.02$ ) (Table I). In addition, mucosal abnor-

(C) The Fellowship of Postgraduate Medicine, 1986 
Table I Results of barium meal examinations

\begin{tabular}{|c|c|c|c|c|}
\hline & \multicolumn{4}{|c|}{ Referral source } \\
\hline & \multicolumn{2}{|c|}{ General practitioner } & \multicolumn{2}{|c|}{ Out-patient department } \\
\hline & No. $(\%)$ & Male/female ratio & No. $(\%)$ & Male/female ratio \\
\hline Normal & $60(40)$ & 0.8 & $82(54)$ & 0.7 \\
\hline Abnormal & 90 (59) & & $68(45)$ & \\
\hline Mucosal* & $64(42)$ & 1.8 & $34(22.5)$ & 1.6 \\
\hline $\begin{array}{l}\text { Structural/ } \\
\quad \text { functional** }\end{array}$ & $26(17)$ & 0.5 & $34(22.5)$ & 1.6 \\
\hline Equivocal & $2(1)$ & 1.0 & $2(1)$ & 2.0 \\
\hline
\end{tabular}

* Carcinoma, ulcer, scarring, duodenitis, gastritis, pyloric stenosis, oesophageal stricture and oesophagitis.

** Hiatus hernia, reflux, diverticula, tertiary contractions in oesophagus.

malities were more common in GP than hospital patients $\left(42 \%\right.$ vs $\left.22.5 \% ; \chi^{2}=13.5, P<0.001\right)$. In both GP and OP groups mucosal abnormalities were more common in men. Four carcinomas (3 gastric, 1 oesophageal) were found in the 304 examinations $(1.3 \%)$. All four patients were GP referrals and over 50 years of age. In addition $72 \%$ of all ulcers were referred by GPs.

Normal examinations were more common in patients less than 50 years of age, being $56 \%$ and $61 \%$ for GP and OP referrals respectively (Table II). Mucosal abnormalities however, occurred with similar prevalence in men $30-50$ years of age $(37.5 \%$ and $17 \%$ for GP and OP respectively) and in those less than 30 years ( $40 \%$ and $33 \%$ respectively) (Table III). Hospital out-patient referrals came equally from medical and surgical clinics and there was no difference in diagnostic yield between patients referred from these sources.

\section{Discussion}

The present study shows that significantly more mucosal abnormalities are present in GP referrals for double-contrast barium meal examination than in OP referrals, indicating an effective use by GPs of an expensive hospital service speciality. The reason for this difference cannot be determined by present or previous studies but probably reflects differences in the pattern of disease presentation to the GP and hospital doctor. One might speculate that the GP often requests barium meal examination to confirm a strongly suspected clinical diagnosis whereas the hospital doctor is often seeing less straightforward referrals, many of whom will have functional symptoms and thus expects a proportion of examinations to be normal. This expectation of a normal result in no waye detracts from the value of the examination. The normal result allays patient anxiety, increases management confidence and narrows potential differential diagnosis (Gorry et al., 1978). Indeed the value of the normal examination should not be underestimated as it can also be effective with respect to changes in management. Mead et al. (1977) found that $55 \%$ of their management changes in 100 dyspeptics under 50 years of age were in patients with normal barium meal examination.

In our study, erosions, duodenitis and oesophagitis accounted for $19 \%$ (19 of 98 ) major abnormalities in

Table II Results of barium meal examinations related to patients' age

\begin{tabular}{|c|c|c|c|c|}
\hline & \multicolumn{4}{|c|}{ Referral source } \\
\hline & \multicolumn{2}{|c|}{$\begin{array}{c}\text { General practitioner } \\
\text { No. }(\%)\end{array}$} & \multicolumn{2}{|c|}{$\begin{array}{c}\text { Out-patient department } \\
\text { No. }(\%)\end{array}$} \\
\hline & $<50$ years & $>50$ years & $<50$ years & $>50$ years \\
\hline Normal & $43(56)$ & $17(23)$ & $47(61)$ & $35(47)$ \\
\hline Abnormal & $33(43)$ & $57(76)$ & $30(39)$ & $38(51)$ \\
\hline Mucosal & $23(30)$ & $41(55)$ & $17(22)$ & $17(23)$ \\
\hline \multicolumn{5}{|l|}{ Structural/ } \\
\hline functional & $10(13)$ & $16(21)$ & $13(17)$ & $21(28)$ \\
\hline Equivocal & $1(1)$ & $1(1)$ & $0(0)$ & $2(2)$ \\
\hline Total & 77 & 75 & 77 & 75 \\
\hline
\end{tabular}


Table III Prevalence of barium meal mucosal abnormalities in younger patients

\begin{tabular}{llccc}
\hline & $\begin{array}{c}\text { Age } \\
\text { (years) }\end{array}$ & No. & $\begin{array}{c}\text { Reneral practitioner } \\
\text { Mucosal abnormality } \\
\text { No. }(\%)\end{array}$ & $\begin{array}{c}\text { Out-patient department } \\
\text { Mucosal abnormality } \\
\text { No. }(\%)\end{array}$ \\
\hline Men & $30-50$ & 24 & $9(37.5)$ & $4(17.0)$ \\
Women & $<30$ & 15 & $6(40.0)$ & $5(33.0)$ \\
& $30-50$ & 23 & $5(22.0)$ & $6(26.0)$ \\
Total & $<30$ & 15 & $3(20.0)$ & $2(13.0)$ \\
\hline
\end{tabular}

comparison with Haines et al. (1980) who found that only $2 \%$ of barium meal abnormalities in their patients were of the superficial inflammatory type. This is probably due to the fact that double-contrast barium meals were performed in only $13 \%$ of the latter series but used in all patients in the present study. The double-contrast barium meal gives better mucosal detail and increases the likelihood of detecting superficial mucosal lesions (Herlinger et al., 1977).

In a previous study of 100 dyspeptics under 50 years of age (Mead et al., 1977), 76\% of barium meal examinations were normal. In patients less than 30 years, only $10 \%$ had a barium meal abnormality compared with $30 \%$ in the $30-50$ year age group. We found, however, that $26.6 \%$ of patients below 30 years had mucosal abnormalities. These abnormalities occurred more frequently in men and in GP rather

\section{References}

COOK, P.L. (1966). Experiences in the first year of an 'opendoor' X-ray department. British Medical Journal, 2, 351.

GORRY, G., PAUKER, S. \& SCHWARTZ, W. (1978). The diagnostic importance of the normal finding. New England Journal of Medicine, 298, 486.

HERLINGER, H., GLANVILLE, J.N. \& KREEL, L. (1977). An evaluation of the double contrast barium meal against endoscopy. Clinical Radiology, 28, 307.

HAINES, A.P., ASHLEIGH, R., BATES, R. \& KREEL, L. (1980). than hospital referrals. Active duodenal ulceration was found in almost one-third of men under 30 years of age, which is substantially higher than that reported previously (Mead et al., 1977) and may reflect differences in examination technique or even increasing disease incidence.

Thus the value of barium meal examination in the younger patient may have been underestimated in the past, although practice regarding the use of this examination does not seem to have been influenced significantly by this earlier study (Mead et al., 1977). The precise relationship between $\mathrm{H}_{2}$-receptor antagonist use and barium meal requests and the vexed question as to what is the management value of a normal examination cannot be answered by the present study but is currently under prospective evaluation at this hospital.

The use of barium meals by general practitioners and hospital doctors. Journal of the Royal College of General Practitioners, 30, 97.

MEAD, G.M., MORRIS, A., WEBSTER, G.K. \& LANGMAN, M.J.S. (1977). Uses of barium meal examination in dyspeptic patients under 50. British Medical Journal, 1, 1460.

WRIGHT, H.J., SWINBURNE, K. \& INCH, J. (1977). The general practitioners use of diagnostic radiology. Journal of the Royal Society of Medicine, 72, 88. 